\title{
AUTOMATIC RISK CONTROL BASED ON FSA METHODOLOGY ADAPTATION FOR SAFETY ASSESSMENT IN INTELLIGENT BUILDINGS
}

\author{
JERZY MIKULIK, MIROSŁAW ZAJDEL
}

Department of Management and Systems Engineering

AGH University of Science and Technology, ul. Gramatyka 10, 30-067 Cracow, Poland

e-mail: jmikulik@zarz.agh.edu.pl,mzajdel@agh.edu.pl]

\begin{abstract}
The main area which Formal Safety Assessment (FSA) methodology was created for is maritime safety. Its model presents quantitative risk estimation and takes detailed information about accident characteristics into account. Nowadays, it is broadly used in shipping navigation around the world. It has already been shown that FSA can be widely used for the assessment of pilotage safety. On the basis of analysis and conclusion on the FSA approach, this paper attempts to show that the adaptation of this method to another area-risk evaluating in operating conditions of buildings-is possible and effective. It aims at building a mathematical model based on fuzzy logic risk assessment with different habitat factors included. The adopted approach lets us describe various situations and conditions that occur in creating and exploiting of buildings, allowing for automatic control of the risk connected to them.
\end{abstract}

Keywords: risk, formal safety assessment, fuzzy logic, intelligent building.

\section{Introduction}

Nowadays the progress of technology allows us to create autonomous, adaptive automated systems capable of making decisions in a given context. These systems cannot be reduced to the simple concept of process, but should be rather considered as sets of objects working together in a specified environment to accomplish determined functions. For this reason, studying the behavior of such complex systems like agglomerations of intelligent buildings is difficult and should be based on the analysis of the environmental conditions set and in cooperation with mathematical methods of risk control (Mikulik et al., 2005).

The safety of technical and technological structures has been more and more often the aim of many analyses and research works. Its importance is generally recognized and respected. It is widely known that beside many useful goods and services, technology brings about some hazards. They concern especially our habitat, either marine airspace or ground environment. They concern also our security level in using such technological objects and the security of objects themselves, because destructing the influence of the environment on them is noticeable at every step (Mikulik and Boryczko, 2002).

A fuzzy probabilistic approach is gaining popularity in evaluating the conditions of the environment and effects of the influence which technical objects exert on the environment. Some useful methods of probabilistic evaluation of environment conditions have been presented and already classified based on how strongly they rely upon probabilistic measures and probability theory or fuzzy logic (Truemper, 2004). A global treatment method the three sources of vagueness (randomness, fuzziness and errors) has also been proposed and is taken into consideration in every method of risk assessment in specific environment conditions. According to this classification, the way of evaluating of environmental conditions usually has two aims:

- theoretical-recognition of environment components, their characteristics and spatial or temporal changeability,

- practical-research, what kind of results we are able to achieve from theoretical recognition, and what we can say about environmental impact and technological influence on the environment.

It has been shown that the best way of evaluating conditions of the environment is cartographic studies (Drągowski, 2004). Nevertheless, with reference to the above mentioned aims there is a more and more meaningful need to express detailed information about environment characteristics of technological objects (such as city, 


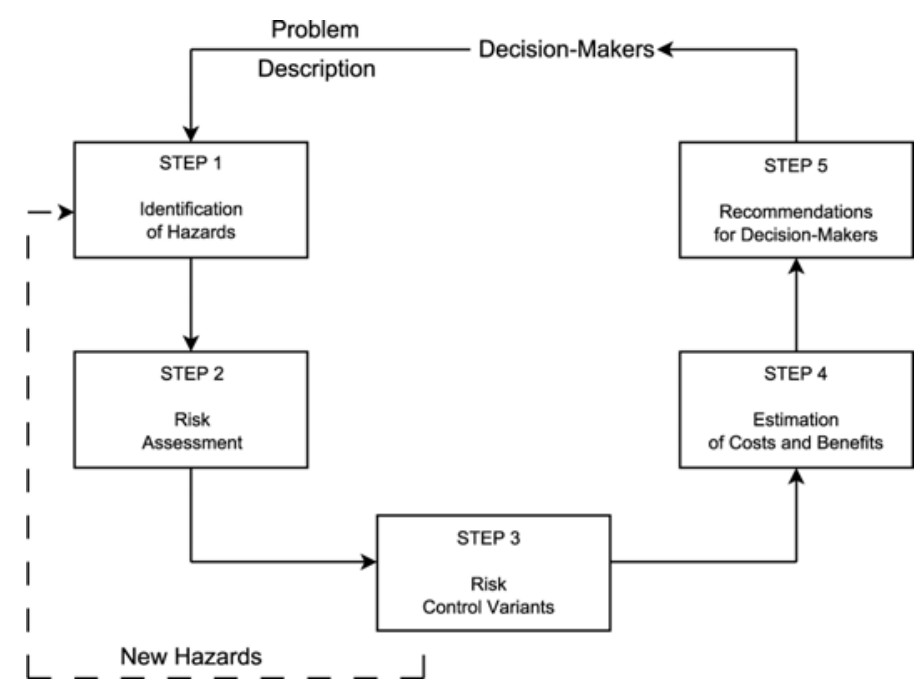

Fig. 1. Five-step procedure pattern loop and workflow schema in formal safety assessment.

estate, industrial plant, household, etc.) with taking into consideration also uncertainty. It is a strong aspect of research, since there is no assessment of some conditions, which is absolutely certain. Rather it is certain to a specific degree and only similar to the absolute truth. Hence to satisfy these demands, methods named probabilistic assessments have been created. They are often found as best in their class and are given the highest trust by experts in the risk evaluation domain (Hauryłkiewicz, 2005).

\section{Further motivations}

Everywhere in the world there are built-up areas subjected to effects of the environment. Natural disasters occur in many populated territories and cause huge material losses and casualties. Typhoons in the Far East, floods and mud avalanches in Asia, avalanches on numerous mountain areas, earthquakes and many other factors contribute to human problems with maintaining safe buildings.

However, not only are such terrible environmental influences reasons for building destruction. Geological research and weather forecasting are often unreliable, and even ordinary average hazard factors bring about some destructions when we are not able to prepare for them early enough and properly (Mikulik et al., 2007).

Insurance companies, groups of risk prevention, building companies and legislation organizations strive for adequate methods and tools for risk assessment and control in such areas of investigation for human safety. In order to prevent accidents and increase security standards, there have been prepared a few methods which are helpful in decision making under dangerous conditions (Mikulik and Zajdel, 2008). Formal Safety Assessment (FSA) collects them and offers one, strictly formal method, gathering all the best that has been worked out up till now. This work tries to point at a new way of making use of FSA in human security in the form of intelligent buildings with hazards as insignificant as possible.

There are plenty of intelligent building definitions and their characteristics depend strongly on the professional preparation of the person who formulates the definition. There are definitions prepared by computer scientists, control engineers or economists. An intelligent building is not only a physical object but also constitutes a friendly environment for humans using it. It is also friendly for natural environment surrounding it and is able to watch either its interior or surroundings. All the procedures of the control of intelligent buildings are carried out providing the optimization of technical and economic processes, and also maintaining the highest level of security.

Intelligent buildings are equipped with technical intelligence and each of their control and executive parts has the same components as a typical personal computer. Therefore, as technical intelligence we can define the ability of these buildings to collect and process data and information. For intelligent buildings most important is simplicity of functionality, which can be achieved by integrating all the technical and security subsystems.

An intelligent building can be considered as a system composed of a natural and an artificial environment, people and technology. In such a big and complicated system running in real time some undesirable accidents may occur. That is why the management of intelligent building security has to have a professional nature and be based on effective methods and approaches (Mikulik, 2008).

\section{Methodology overview}

Formal safety assessment is a systematic, formal and integrated assessment approach being used by insurance companies mainly for the estimation of sea navigation security. The main aim of this methodology is to improve 
the level of maritime safety connected with either life and health security or the environment and property protection. It is most useful in making decisions using risk analysis, the estimation of costs and profits, and also creating decision trees.

The objective of FSA is the development of a framework of safety requirements in which risks are addressed in a comprehensive and cost-effective manner. It is possible to achieve such aims thanks to a methodology that is based on the principles of identifying hazards, evaluating risks and cost-benefit assessment. Having been generally and formally approved to primarily verify the effectiveness of the proposed rules and regulations, the FSA technique applies its broad principles of quantitative risk assessment in five steps (Soares and Teixeira, 2001) as follows:

Step 1. Identification of hazards.

Step 2. Risk assessment.

Step 3. Risk control variants.

Step 4. Estimation of costs and benefits.

Step 5. Recommendations for decision makers.

Effective management of formal safety assessment emphasizes that there needs to be established a loop between these five steps, whereby effects of changes based on decision making in Step 5 are monitored to ascertain whether the desired level of safety can be achieved. If not, further options ought to be examined. The main loop and workflow in FSA is presented in Fig. 1. The core process of FSA comprises five steps, so the objective can be achieved by carrying out rational analyses during all of them, which facilitates systematic judgment and effective risk management (Soares and Teixeira, 2001).

As a method supporting decision making for risk control, FSA offers a more rational approach than traditional methods, which use their patterns in the regulation by disaster way. Meanwhile, compared with other assessment methods, this methodology is more formal, reasonable and integrated than traditional means. FSA can be also applied to the analysis and evaluation of both actual hazards after the occurrence of accidents and potential events before their occurrence (Hu et al., 2007). FSA gives the opportunity to gain as much security as possible through the selection of the risk control variant, which yields huge risk reduction and good financial benefits, since FSA not only judges whether and how each means applied is helpful in gaining a higher security level or lower pollution level, but it also estimates costs of operations. Furthermore, this methodology keeps good cognition of precautions through detailed identification who or what is the real cause of the risk, who will take advantage of risk control and reduction and who will bear costs (Wang, 2001).

Since formal safety assessment has been introduced into the ship-safety field, it has proved to be a method widely applicable, detailed in statistical analysis and effective in assessment, featured by formal operation procedures, serial standard analysis techniques and decision making based on cost-benefit assessment. During the last few years, it has also been adapted to some other fields in which risk estimation plays a significant role, such as pilotage, environment protection and public transport. In the next section we try to show how to use FSA methodology as a helpful tool for the creation of the arrangement and usage plan for intelligent buildings. All five steps of FSA with their main aspects are described in detail; however, the risk assessment is a critical step and the core process among other categories in the establishment of the risk model.

\section{FSA five-step adaptation}

4.1. Identification of hazards. In relation to safety, risk is the description of hazards for the analyzed subject. As a hazard we can describe a situation which causes danger or damage to an object or the environment. Indispensable for the reduction of hazard is their identification, which is to be done in Step 1 of formal safety assessment. Scenarios of accidents and effects of recognized hazards are worked out, and then they are given ranks for each scenario and each hazard. Next, the ranks are verified. There are three more sub-steps which the current step consists of.

4.1.1. Problem definition. The problem should be carefully described and there should be limits characterized. The main aim is to recognize the environment and objects, which form a basis for our discussion, as well as possible under the imposed needs. The domain should be analyzed either under current conditions, or possible changes ought to be considered.

4.1.2. Hazard identification. Taking advantage of the problem definition, the main hazards should be identified. Usually there are no known connections or relationships between dangerous factors, but the effects of specific properties are possible to estimate. Thus, recognizable reasons and accidents connected with them are specified in this step. While evaluating possible variants, the synthesis of conceivable effects is made through appealing against experience in real events.

There are many possible ways in which the environment and objects such as buildings affect each other. While these processes are in progress, mainly the parameters of the building, called its resource of functionality, are 


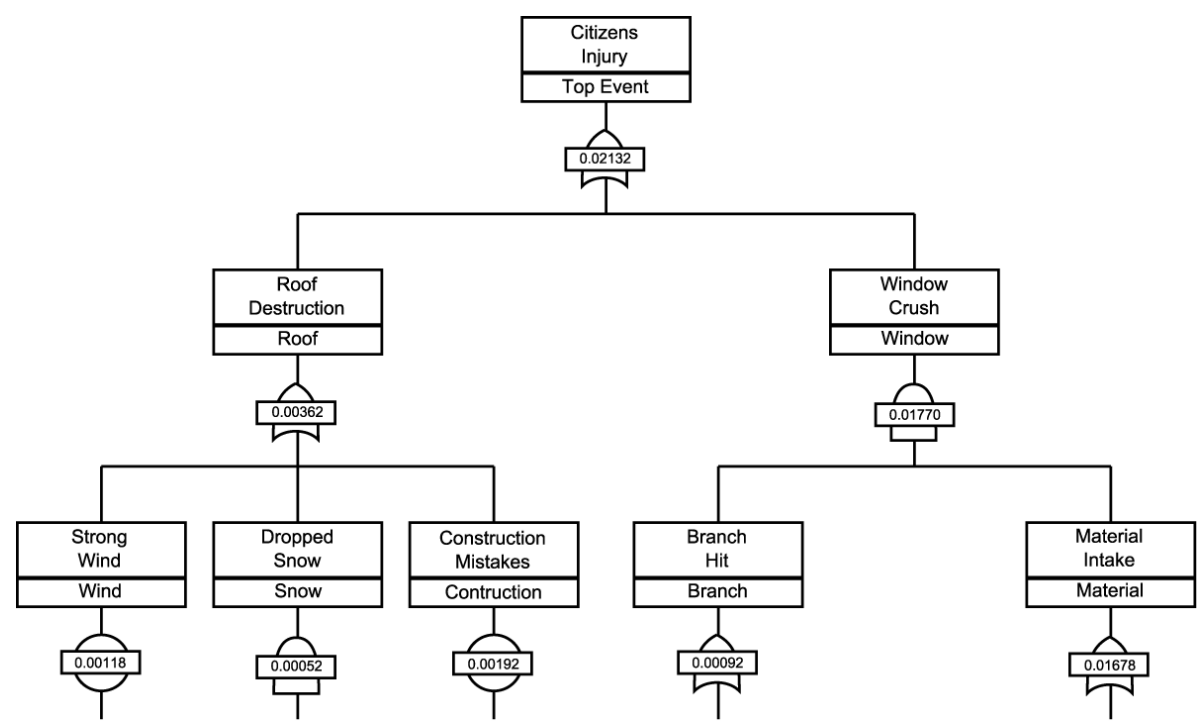

Fig. 2. Example of the FTA tree for a citizen injury event.

changing. The exhaustion of the functionality resource of the building is thus caused by the energy flow between the object and the environment. Our task in this step is to describe these possible ways of mutual influence.

How important it is to find all probable sources of hazards is seen in the hypothesis that in a building, which is a technological object changing with time, the speed of the change measured with appropriate characteristics of the object depends on the energy needed to activate the reaction occurring in the object, according to the following equation:

$$
\ln S=\ln S_{0}-K t e^{-\frac{Q}{E}},
$$

where $S$ denotes the durability after time $t, S_{0}$ is the initial durability, $K$ is a reactionary constant, $Q$ means the activation energy of reaction and $E$ stand for the energy delivered by the environment to the object (Dwiliński, 2006).

The expression above indicates that the durability of the object connected with a specific environmental, being a continuous factor, differs exponentially with time. Thus, environmental influence on buildings is far more greater than the energy flow, so taking into consideration even a seemingly insignificant factor is very important.

The description of hazards is allowed to be made through choosing a few from among some different ways. They are usually created during hazard and operability study (HAZOP meetings), which is one of the universal, analytical methods in gaining information about the possibility of hazard occurrence. There are reasons and possible effects analyzed, and presented as a special kind of tree structures. It is suggested in the literature to use for reasons of hazards Fault Tree Analysis (FTA), which takes advantage of tree structures to decompose system levels into combinations of lower-level events, and Boolean gates to model their interactions. However, for effects of hazards there ought to be used Event Tree Analysis (ETA), which is employed to determine the path from an initiating event to various consequences, and the expected frequency of each consequence (MEPC, 2000). The examples of FTA and ETA trees for the destruction of building roof event are presented in Figs. 2 and 3 .

Input data needed for the creation of tree structures are, among other things, probabilities of appropriate events and their causes. Thus, gaining such information as the reliability of building materials is indispensable. It should be achieved through the analysis of historical and statistical data, expert opinions and tests of reliability made in laboratories.

4.1.3. Hazard analysis. This sub-step is, after hazard identification, the most important part of first step of FSA and constitutes an introduction to risk assessment. It is connected with exchanging written information with mathematical interpretation as a quantitative model of risk. Hazard analysis considers statistical and probabilistic data describing known facts from the exploitation of the domain.

The main aim here is good reconnaissance of the environment and, to this end, gathering probabilistic data for further investigation is necessary. The sources of data may be archival statistical data or experts' opinions. After the identification of hazards we are able to gain information about each one and attribute frequency and effects to them. During Step 2 these numerical data will turn into a risk model, which is made up of the data and fuzzy logic application. 


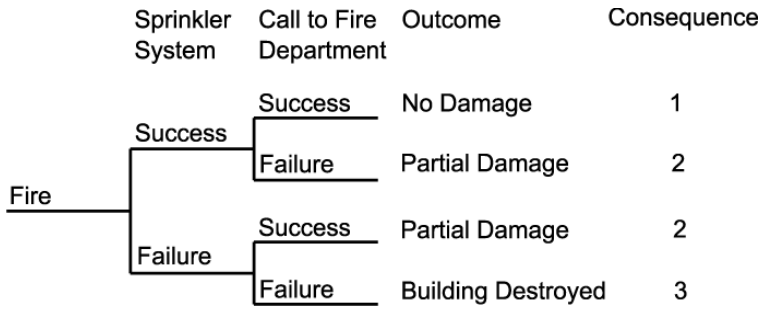

Fig. 3. Example of the ETA tree for a fire event.

4.2. Risk assessment. This is the most important step in the whole FSA method. It is connected with designing the computational model for risk estimation, based on the description of the energy flow between buildings and the environment. The identification of the risk resulting form hazards is made in Step 1. There are important scenarios indicated in the previous step being considered and the amount of risk occurring in each scenario is computed. Through the analysis, factors which may have essential influence on the risk level are identified, and thus the attention is focused on the most important reasons for the risk.

The main aims of this step are to generate and specify risk profiles, present them in a form which is important and useful for other steps and decision makers in Step 5, and finally to specify changes in the risk as a result of potential employment of the variants of risk control in Step 3.

4.2.1. Generic risk assessment model. Generally speaking, risk is a measure of danger severity for the analyzed building, which is mainly concerned with two aspects. First, risk is considered as the possibility of the occurrence of hazardous or abnormal accidents. Second, risk is also considered as a consequence involved in damages resulting from these hazardous or abnormal accidents. Thus, risk possesses a dual nature and can be characterized by possibility $(P)$ and severity $(S)$ according to the equation

$$
R=f(P, S) .
$$

When it comes to possibility, it is characterized by the frequency of specific event occurrence. Thus statistic data, describing frequency, are needed to compute possibility elements and to describe possible occurrences of hazardous accidents. Concerning building security, possibility can be viewed as the ratio of the number of accidents to the number of buildings per unit time in the investigated area. The corresponding equation is then

$$
P=\frac{\sum_{i} A_{i}}{\sum_{i} B_{i}},
$$

where $\sum_{i} B_{i}$ denotes the total number of buildings in the area of interest and $\sum_{i} A_{i}$ denotes the total number of buildings affected by accidents.

Severity is used to describe the consequences of damages caused by hazardous accidents. The quantification of severity is a complicated issue in safety assessment. The study and analysis are carried out from different perspectives. Therefore, there are different involvement ranges the quantitative analysis of severity. In practice, many various risks shall be involved in the analysis of severity, such as risks against people, the environment and economic damages. Concerning intelligent buildings, severity for accidents is the ratio of consequences against the accident number per unit time. The equation characterizing this statement is

$$
S=\frac{\sum_{i} C_{i}}{\sum_{i} A_{i}},
$$

where $\sum_{i} A_{i}$ denotes the total number of buildings affected by accidents and $\sum_{i} C_{i}$ denotes the total value of severity (consequences), which is a negative effect of accident.

Quantitative estimation of severity is really hard, but it is necessary in FSA progress to evaluate severity in accordance with its quantitative analysis. Generally, severity is here described using fuzzy logic, because this is the only way for well-established evaluation of severity, affected by a relatively small fault during further computations. The literature recommends logarithmic value estimation of severity to be made as shown in Tab. 1] $(\mathrm{Hu}$ et al., 2007). To involve suitably both the frequency and severity of accidents in the assessment, the risk matrix method is used FSA analysis (MEPC, 1997). As an efficient method of risk analysis of individuals, risk matrices can describe two factors of risk (frequency and severity of

Table 1 . Severity value table for hazardous accidents.

\begin{tabular}{|l|l|l|}
\hline Grade & Value $\left(A_{i}\right)$ & Description \\
\hline \hline catastrophic & 100 & $\begin{array}{l}\bullet \text { total loss } \\
\bullet \text { many fatalities }\end{array}$ \\
\hline major & 10 & $\begin{array}{l}\bullet \text { major casualties } \\
\bullet \text { single fatality or } \\
\text { multiple severe injuries }\end{array}$ \\
\hline minor & 1 & $\begin{array}{l}\bullet \text { local damage } \\
\bullet \text { marginal injuries }\end{array}$ \\
\hline insignificant & 0.1 & $\begin{array}{l}\bullet \text { repair needy failure } \\
\bullet \text { no significant } \\
\text { harm to people }\end{array}$ \\
\hline
\end{tabular}


accidents for $n$ buildings) as

$$
\begin{aligned}
& \mathbf{P}=\left[\begin{array}{lllll}
\frac{A_{1}}{B_{1}} & \ldots & \frac{A_{i}}{B_{i}} & \ldots & \frac{A_{n}}{B_{n}}
\end{array}\right], \\
& \mathbf{S}=\left[\begin{array}{lllll}
\frac{C_{1}}{A_{1}} & \ldots & \frac{C_{i}}{A_{i}} & \ldots & \frac{C_{n}}{A_{n}}
\end{array}\right],
\end{aligned}
$$

where $\mathbf{P}$ and $\mathbf{S}$ denote respectively the matrices of probability and severity.

Furthermore, hazards can be accumulated to risk using Eqn. (2), and the most obvious expression connecting Eqns. (2) and (5) is a Cauchy product,

$$
\mathbf{R}=\mathbf{P} \times \mathbf{S}^{T}=\sum_{i=1}^{n} \frac{C_{i}}{B_{i}} .
$$

It is worth noticing that this kind of risk estimation makes it possible, for risk for buildings in a certain area to be calculated by accumulating risks from a few component parts of this area. Consequently, analysis may concern only one factor of hazard, a few factors or all of the factors in the area.

Risk according to calculated outcomes can be classified into three different fuzzy categories, namely, negligible risk, risk as low as reasonably possible and intolerable risk. Such classification is then passed on to further steps.

However, the generic risk model has a few disadvantages that often limit or even eliminate its usefulness:

- it is hard to gather accurate data for major accidents with many fatalities,

- many poorly developed or dictatorship-type countries hide or change real data in order to avoid international embarrassment,

- history of statistical data is not too long,

- building and construction industry quickly changes with time, thus many parts of data may become useless,

- generic model does not take into consideration the obligated severity connected with expected behavior of the environment,

- statistical span of the generic model is great, and risk levels of research subjects in the analysis are quite intensive, so it is not easy to collect a detailed quantity of data for building exploitation so as to effectively identify the main risk problems.

Thus, in order to show the frequency and severity of the main hazardous events in a Poisson process, it is necessary to build a relative risk assessment model to better understand the construction and influential factors of risks (Hu et al., 2007). Therefore, it is required that a risk assessment model based on more factors should be built in order to further expand the practicability of the model. Such a model solves problems on the basis of fuzzy functions and will be presented below.

4.2.2. Relative risk assessment model. Generally speaking, risk configuration for one, specific environmental hazard, based on the relative criterion of the determined severity natures, in association with the computing method of the risk matrix in the generic model can be established generally as a Hadamard product

$$
\mathbf{R}=\sum_{i=1}^{m} \mathbf{R}_{i} \cdot \mathbf{W}_{i},
$$

where $\mathbf{R}_{i}$ denotes risk presented as a set of important parameters and $\mathbf{W}_{i}$ denotes weights of these parameters.

Taking relative relations and multiple hazards into consideration, the configuration of risk for $m$ hazard sources in the investigated area during the analyzed period of time can be computed using the risk parameters matrix and weights matrix as follows:

$$
\begin{aligned}
& \mathbf{R}_{i}=\left[\begin{array}{lll}
\mu_{F}\left(x_{F i}\right) & \mu_{S}\left(x_{S i}\right) & \mu_{R}\left(x_{R i}\right)
\end{array}\right. \\
& \left.\mu_{S_{o}}\left(x_{S_{0 i}}\right) \quad \mu_{R_{o}}\left(x_{R 0 i}\right)\right] \text {, } \\
& \mathbf{W}_{i}=\left[\begin{array}{lllll}
\omega_{F i} & \omega_{S} & \omega_{R} & \omega_{S_{o}} & \omega_{R_{o}}
\end{array}\right], \\
& \forall j \in\left\{F, S, R, S_{o}, R_{o}\right\}: \quad \sum_{i=1}^{m} \omega_{j_{i}}=1, \\
& \forall 1 \leq i \leq m: \quad \sum_{j} \omega_{j_{i}}=1,
\end{aligned}
$$

where $\mathbf{R}_{i}$ denotes the matrix of membership functions $\mu_{j}\left(x_{j_{i}}\right)$ of a fuzzy logic set $\mu$ calculated as a value dependence degree under five different factors: $\mu_{F}$-frequency, $\mu_{S}$-relative severity, $\mu_{R}$ - the nature of risks, $\mu_{S_{o}}$ obligated severity entailed by accidents, $\mu_{R_{o}}$ the obligated risks entailed by accidents. Values of $\omega$ represents respective weights of parameters

These factors $\mu_{j}\left(x_{j_{i}}\right)$ involved in the relative model of risks would be determined as five factors based on different environmental conditions and different building states, which in building exploitation include the frequency and severity of accidents, the nature of risks, obligated severity entailed by accidents and relative obligated risk entailed by accidents.

With respect to building exploitation, there are three types of involvement ranges for the severity of hazards:

- from the perspective of life, severity involves life losses caused by accidents, including deaths and human injuries,

- from the perspective of property, severity involves direct economic damages caused by accidents, 
- from the perspective of pollution, it involves environmental pollution damages caused by accidents of some industrial buildings.

Furthermore, risk can be presented accumulating Eqns. (7) and (8) as a set of five specific parameters according to the equation

$$
\begin{gathered}
\mathbf{R}=\left[\begin{array}{lllll}
\mu_{F} & \mu_{S} & \mu_{R} & \mu_{S_{o}} & \mu_{R_{o}}
\end{array}\right], \\
\forall j \in\left\{F, S, R, S_{o}, R_{o}\right\}: \quad \mu_{j}=\sum_{i=1}^{m} \mu_{j}\left(x_{j_{i}}\right) \omega_{j_{i}},
\end{gathered}
$$

where risk is a risk configuration profile, representing risk status in the investigating area. For each hazard, relative risk would be analyzed according to a membership function. In addition, ranked critical values of the corresponding membership of the configuration of the corresponding factors together would be determined separately.

Evaluation of $\mu_{j}\left(x_{j_{i}}\right)$ is performed as follows. Introduce a mapping in universe $U, \mu: U \rightarrow[0,1]$, $x_{j_{i}} \rightarrow \mu_{j}\left(x_{j_{i}}\right)$, where $\mu$ is a fuzzy logic set in $U$ and $\mu_{j}\left(x_{j_{i}}\right)$ is a membership function of $\mu$. The fuzzy relation would be determined as

$$
\mu_{j}\left(x_{j_{i}}\right)=\frac{x_{j_{i}}}{\kappa+x_{j_{i}}}, \quad x_{j_{i}} \geq 0
$$

where $\kappa$ denotes the average value of parameter $x_{j}$ taking into consideration periods of time (due to the specification of historical data, it is usually one year) and $x_{j_{i}}$ is the most characteristic parameter which best describes hazard connected to it during the scheduled time of calculation as a function $\mu_{j}$.

Notice that if $x_{j_{i}}=\kappa$, the characteristic parameter equals the average of those which have been judged,

$$
\mu_{j}\left(x_{j_{i}}\right)=\frac{x_{j_{i}}}{\kappa+x_{j_{i}}}=\frac{\kappa}{\kappa+\kappa}=0.5,
$$

and therefore, the membership of $\kappa$ equals 0.5 . However, the starting point for grading the values $x_{j}$ is criteria tables. They should be created suitably according to the specificity of each hazard. The proposed criteria tables for frequency and relative severity are presented in Tables 2 and 3 (Hu et al., 2007).

4.3. Risk control variants. The next step of formal safety assessment is connected with the most important factors of risk. Attention is focused on those which cause the highest risk level. First of all, they have to be analyzed taking into consideration the following coefficients:

- high level of risk,

- high severity,

- high probability,
- low confidence.

Next, all means of control are identified so that the control of risk, calculated in Step 2, could possible. Taking into consideration either risk which occurred in the past or risk which could occur in the future, effective and practical variants of the control of the investigating domain are established. For each option, foreseen reductions in risk as after-effects of given possibilities are estimated. Finally, a register of all variants of risk control with effective risk reduction is gained, which is particularly analyzed in Step 4.

4.4. Estimation of costs and benefits. The aim of the fourth step of the FSA method is the analysis of each control variant. To this end, all steps and advantages for each variant identified in Step 3 are defined. The results are expressed as discounted net values with reference to the life cycle of the building.

For this kind of variant estimation, the CBA operating method is applied. Cost-benefit analysis is an informal approach to making decisions of any kind. The process involves, whether explicitly or implicitly, weighing the total expected costs against the total expected benefits of one or more actions in order to choose the best or the

Table 2. Frequency (probability) criteria table.

\begin{tabular}{|l|l|l|}
\hline Grade & Value $\left(\mu_{P}\right)$ & Description \\
\hline \hline frequent & 0.001 & $\begin{array}{l}\text { frequently happened } \\
\text { during an activity }\end{array}$ \\
\hline $\begin{array}{l}\text { reasonably } \\
\text { probable }\end{array}$ & 0.0001 & $\begin{array}{l}\text { possibly happened } \\
\text { during an activity }\end{array}$ \\
\hline remote & 0.00001 & $\begin{array}{l}\text { occasionally happened, } \\
\text { but not often }\end{array}$ \\
\hline $\begin{array}{l}\text { extremely } \\
\text { remote }\end{array}$ & 0.000001 & $\begin{array}{l}\text { almost would not } \\
\text { have happened } \\
\text { during an activity } \\
\text { but should not } \\
\text { exclude the existence }\end{array}$ \\
\hline
\end{tabular}

Table 3. Relative severity criteria table with reference to the life perspective.

\begin{tabular}{|l|l|l|}
\hline Grade & Value $\left(\mu_{S}\right)$ & Description \\
\hline \hline $\begin{array}{l}\text { extraordinary } \\
\text { serious }\end{array}$ & 50 & teens fatalities \\
\hline very serious & 10 & many fatalities \\
\hline serious & 5 & $\begin{array}{l}\text { single fatality or } \\
\text { multiple severe injuries }\end{array}$ \\
\hline less serious & 1 & $\begin{array}{l}\text { marginal injuries } \\
\text { to crew }\end{array}$ \\
\hline slight & 0.1 & small harm to people \\
\hline incident & 0.05 & $\begin{array}{l}\text { no significant harm } \\
\text { to people }\end{array}$ \\
\hline
\end{tabular}


most profitable option. This method is widely available, acceptable and applied. It generates helpful information assisting decision process but could not identify the best way of reaction by itself.

The analysis starts with gathering all the information obtained in past steps. Then, from among overall perspective successive operations, the following are conducted:

- evaluating the costs of the variant,

- evaluating the profits of the variant,

- linking the costs and profits to likely reduction in the risk.

Costs evaluation for each variant should include such expenses as the cost of compliance, operations, training, enforcement, legislation, control, certification, etc. However, the assessment of profits has to be measured in categories such as the reduction of hazard frequency, and accident frequency, the growth of the building life cycle, the reduction of environmental damage or environment regeneration costs. In order to make sure that the overall assessment was made properly, the inspection of risk control variants characteristics has to be done and other evaluations have to be performed.

The last thing to do is to specify net variants costs as a difference between overall costs of a specific variant and its financial profits. For each variant, there are Cost per Unit of Risk Reduction (CURR) indicators calculated according to the equation

$$
\text { CURR }=\frac{\text { net cost of variant application (costs) }}{\text { possible risk reduction (profits) }}
$$

It makes if possible to compare variants of risk control, which is a key aspect for working out recommendations for decision makers.

4.5. Recommendations for decision makers. In the last step of formal safety assessment, based on information about hazards, risk, actions variants, costs and profits connected with variants, the proposed, possible methods and their effects are discussed. On the basis of the abovementioned results and a criterion of risk level as low as reasonably possible, recommendations for decision makers of building agglomerations are worked out.

From among many other, as the main results of this step, the following operations occur:

- the most profitable variant of risk control is identified,

- wrongly distributed risk, costs and profits are diagnosed,

- a mechanism for right risk distribution is worked out,
- consequences of applying the most profitable variant are discussed.

Some troubles could appear during this step and one should pay attention to them. Different methods of estimating environmental conditions are full of statistics to various degrees. Expert groups which are to judge the risk environment ought to consider that. The evaluating of conditions is always burdened with some faults. There are three sources of such errors, which have to be taken into consideration during comprehensive probabilistic assessment. They are randomization, carelessness in reconnaissance and mistakes in earlier decisions (Hauryłkiewicz, 2005).

Worth mentioning is one more fact, namely that information which is collected during prior steps is pretty helpful in making decisions. The process of risk evaluation does not weaken the role of decision makers, but delivers to them many useful pieces of information.

\section{Computational example}

Assume that we possess a simple set of probabilistic data for two different buildings as shown in Tables 4 and 6 Building $\mathrm{A}$ is subjected to earthquakes and Building $\mathrm{B}$ is subjected to material fatigue. In order not to complicate, the situation, we do not introduce more hazard sources, so for both buildings $m=1$. Our task is to calculate risk configurations for each building using a relative risk model. Our calculations will be made for a specific moment of the year 2008 .

As we can see, for Building A there are significant losses in victims, which is much more important than physical loss value, which we can neglect. Next, for Building B victims are pretty rare so physical loss value is the main characteristic, which determines the severity of accidents. Therefore, we create for the two buildings two tables, 5 and 7 on the basis of expert opinions, using fuzzy assessment tables analogous to Table 1 for describing levels and the method of extrapolation or estimation for the number of victims or physical loss value.

As we have all the data prepared, we are able to calculate fuzzy functions that risk configuration consists of. We do so according to Eqn. (10), assuming that $x_{i}$ is a

Table 4. Statistical data obtained from historical information for Building A.

\begin{tabular}{|l|l|l|ll|}
\hline Year & $\begin{array}{l}\text { Number of } \\
\text { accidents }\end{array}$ & $\begin{array}{l}\text { Number of } \\
\text { victims }\end{array}$ & $\begin{array}{l}\text { Physical } \\
\text { loss value }\end{array}$ \\
\hline \hline 2004 & 1 & 1 & 200 & $\cdot 10 €$ \\
\hline 2005 & 1 & 2 & 100 & \\
\hline 2006 & 1 & 9 & 700 & \\
\hline 2007 & 2 & 3 & 300 & \\
\hline 2008 & 0 & 0 & 0 \\
\hline
\end{tabular}


value in 2008 and $\kappa$ denotes the average value of the parameter $x_{i}$ taking into consideration all five years time. We are unable to point a more or less important hazard source, because there is only one for each building. Simplifying, we can assume that the weight matrix for both buildings is

$$
\mathbf{W}=\left[\begin{array}{lllll}
1.000 & 1.000 & 1.000 & 1.000 & 1.000
\end{array}\right] .
$$

Therefore, $\mathbf{R}_{1}$ matrices for Building A and for Building $\mathrm{B}$ are calculated as follows:

$$
\begin{aligned}
& \mathbf{R}_{1}^{A}=\left[\begin{array}{lllll}
\frac{0}{0+1} & \frac{0}{0+3} & \frac{10}{10+46} & \frac{5}{5+4} & \frac{1}{1+80.2}
\end{array}\right], \\
& \mathbf{R}_{1}^{B}=\left[\begin{array}{lll}
\frac{3}{3+7} & \frac{450}{450+200} & \frac{100}{100+62.2}
\end{array}\right. \\
& \left.\frac{200}{200+200} \quad \frac{10}{10+2.8}\right]
\end{aligned}
$$

Assuming the weight matrix as in Eqn. (13), the final

Table 5. Fuzzy calculations and estimations based on statistical data for Building A made by experts.

\begin{tabular}{|c|c|c|c|}
\hline Year & $\begin{array}{l}\text { Number of } \\
\text { accidents }\end{array}$ & $\begin{array}{l}\text { Number of } \\
\text { victims }\end{array}$ & $\begin{array}{l}\text { Physical } \\
\text { loss value }\end{array}$ \\
\hline 2004 & 0 & 0 & $\cdot 10 €$ \\
\hline 2005 & 2 & 0 & 250 \\
\hline 2006 & 1 & 0 & 100 \\
\hline 2007 & 1 & 0 & 200 \\
\hline 2008 & 3 & 1 & 450 \\
\hline
\end{tabular}

\begin{tabular}{|l|l|l|l|}
\hline Year & $\begin{array}{l}\text { Estimated } \\
\text { number } \\
\text { of victims }\end{array}$ & $\begin{array}{l}\text { Estimated } \\
\text { risk level }\end{array}$ & $\begin{array}{l}\text { Other hazards } \\
\text { causing } \\
\text { level }\end{array}$ \\
\hline \hline 2004 & & 10 & 100 \\
\hline 2005 & & 10 & 100 \\
\hline 2006 & & 100 & 100 \\
\hline 2007 & & 100 & 100 \\
\hline 2008 & 5 & 10 & 1 \\
\hline
\end{tabular}

Table 6. Statistical data obtained from historical information for Building B.

Table 7. Fuzzy calculations and estimations based on statistical data for Building B made by experts.

\begin{tabular}{|l|l|l|l|}
\hline Year & $\begin{array}{l}\text { Estimated } \\
\text { physical } \\
\text { loss value }\end{array}$ & $\begin{array}{l}\text { Estimated } \\
\text { risk level }\end{array}$ & $\begin{array}{l}\text { Other hazards } \\
\text { causing level }\end{array}$ \\
\hline \hline 2004 & & 1 & 1 \\
\hline 2005 & & 100 & 1 \\
\hline 2006 & & 10 & 1 \\
\hline 2007 & & 100 & 1 \\
\hline 2008 & $200 \quad \cdot 10 €$ & 100 & 10 \\
\hline
\end{tabular}

comparison of risk configurations for both buildings can be presented as

$$
\begin{aligned}
& \mathbf{R}^{A}=\left[\begin{array}{lllll}
0.000 & 0.000 & 0.179 & 0.556 & 0.012
\end{array}\right] \\
& \mathbf{R}^{B}=\left[\begin{array}{lllll}
0.300 & 0.692 & 0.617 & 0.500 & 0.781
\end{array}\right] .
\end{aligned}
$$

On the basis of such comparison and understanding Eqn. (11), we are able to draw conclusions.

There is a pretty strong possibility of the occurrence of some accidents with huge severity in Building A, since both values of parameters for the probability $\mu_{F}$ and the severity $\mu_{S}$ are near zero. The level of danger is high, because the value of the $\mu_{R}$ parameter is between 0 and 0.5 and to it shifted to zero. Expected accidents almost for sure will be connected with a raise in dangerous impact of near hazards sources $\left(\mu_{R_{0}}\right.$ near zero). Nevertheless, the expected severity is average ( $\mu_{S_{0}}$ near 0.5 , as for the average argument value $\kappa$ ), and taking into consideration all the other parameters we can say that the level of security for Building A is pretty low and should be increased as soon as possible, especially due to likely human victims.

The situation is much better for Building B. Only the value of the frequency parameter $\mu_{F}$ is lower than the average value 0.5 . This means that the occurrence of accidents is rather inevitable, but probable severity will be mild (high value of $\mu_{S}$ and average value of the parameter $\mu_{S_{0}}$ ). The level of danger is also rather low (relatively high $\mu_{R}$ ). If any accident happens, it will entail almost no bad consequences in associated hazards and will not increase the risk level. In conclusion, there is no special need to worry about security in Building B at the moment.

\section{Conclusions}

The security of the intelligent building is connected with its exploitation and includes the consideration of all of accidental or intentional dangerous effects coming from the environment or a human. The exploitation of building brings then a lot of hazards to the point of contact between a human and technology or a human and the environment. Each of them, excluding natural disasters, can be caused by accidental or intentional human actions. Unintentional, accidental human faults are the reason for technological failures in the building. It can be also connected with building disasters, the reasons for which are mostly project or executive mistakes. Such faults lead to physical destruction of the building, including its collapse.

In the face of such hazards appearing during building exploitation, suitable strategies of reaction ought to be taken into consideration. A functional system of the intelligent building, made of controlling, executive and dedicated to measurement devices with significant electrical power, is able to take advantage of the FSA method and, as a consequence, to reduce such dangers. 
In this paper, FSA method adaptation for risk control in intelligent buildings was investigated. The research on the application of FSA to prevent building violation or destruction accidents in hazardous areas arrived at some achievements. Safety assessment of building location, especially in relation to environment danger parts of the world, is the requirement of many insurance companies and departments. The key element for reaching adequate results is gaining suitable data. Often in intelligent building domain data are collected as a linguistic variables. Then they are processed into numerical data with some errors. But even if data are hard to obtain and vary a lot with time, the FSA method based on fuzzy sets theory helps to get an acceptable outcome, has great fault tolerance and is insensitive to errors made in swapping linguistic into numerical data, which is the biggest problem in such domains of research.

Practical usage of the FSA method for risk control in intelligent buildings should prove the efficiency of adaptation and confirm the theoretical deliberation. The method can be then applied in risk assessment for insurance and building companies and contractors.

\section{References}

Drągowski, A. (2004). Importance of enigineering geology studies in the environmental impact assessments, Przeglad Geologiczny 52(5): 138-140, (in Polish).

Dwiliński, L. (2006). The Basics of Technical Structures Exploitation, Warsaw University of Technology Press, Warsaw, (in Polish).

Hauryłkiewicz, J. (2005). Probabilistic evaluation of the environment conditions: Methodological issues, Przeglad Geologiczny 53(6): 516-521, (in Polish).

Hu, S., Fang, Q., Xia, H. and Xi, Y. (2007). Formal safety assessment based on relative risks model in ship navigation, Reliability Engineering and System Safety 92(3): 369-377.

MEPC, M. E. P. C. (1997). Interim guidelines for the application of formal safety assessment (FSA) to the IMO rulemaking processes, Technical Report MEPC/Circ. 335, International Maritime Organization, London.

MEPC, M. E. P. C. (2000). Report of the marine environment protection committee on its forty-fifth session, Technical Report MEPC 45/20, International Maritime Organization, London.

Mikulik, J. (2008). Selected Problems of Ensuring Security and Comfort in Buildings, AGH University of Science and Technology Press, Cracow, (in Polish).

Mikulik, J. and Boryczko, T. (2002). Intelligent building as an object integrating electronic systems, Elektronika 43(7/8): 28-31, (in Polish).

Mikulik, J., Pawlik, M. and Blim, M. (2005). Intelligent Building. Part II: Basic Security and Safety Systems in Intelligent Buildings, Silesian University of Technology Press, Gliwice, (in Polish).
Mikulik, J., Pawlik, M. and Blim, M. (2007). The Role and the Meaning of Technical Security Systems in Crisis States. Crisis, Accidents, Disasters in the Context of Threats' Growth, University of Silesia Press, Katowice, (in Polish).

Mikulik, J. and Zajdel, M. (2008). Quantitative and qualitative models for risk assessment in exploitation of ecologically dangerous structures, VISNIK of the East Ukrainian National University Named in Memory of Vladimir Dal Scientific Journal 126(8): 298-303.

Soares, C. G. and Teixeira, A. P. (2001). Risk assessment in maritime transportation, Reliability Engineering and System Safety 74(3): 299-309.

Truemper, K. (2004). Design of Logic-based Intelligent Systems, John Wiley and Sons, New York, NY.

Wang, J. (2001). The current status and future aspects in formal ship safety assessment, Safety Science 38(3): 19-30.

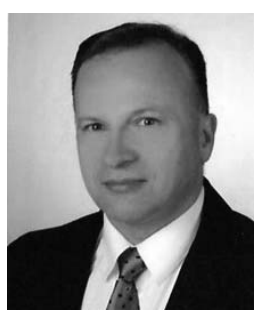

Jerzy Mikulik graduated from the Faculty of Electrical Engineering, Automatics, Computer Science and Electronics of the AGH University of Science and Technology. Currently he works at the Department of Management and Systems Engineering of the same University as the Processes Automation Laboratory manager. Jerzy Mikulik has been researching the theory and practice of security systems in intelligent buildings for many years, and he is an author of many articles and books on the management of the security and comfort of intelligent buildings. Since 2000 he has been the leading organizer of the International Congress on Intelligent Building Systems InBuS, devoted to control systems in intelligent buildings.

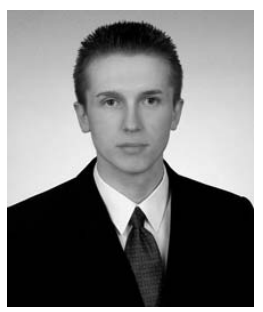

Mirosław Zajdel was born in 1983 in Krosno, Poland. In 2007 he received his M.Sc. degree in computer science with specialization in distributed systems and computer networks from the AGH University of Science and Technology in Cracow. Currently he is a Ph.D. student of computer science at the Faculty of Electrical Engineering, Automatics, Computer Science and Electronics of the same University. His main fields of research are biologically inspired methods of swarm modelling, optimization, and security improvement.

Received: 2 July 2008

Revised: 19 October 2008

Re-revised: 8 November 2008 